David Free

\title{
Stepping through the open door A forum on new modes of information delivery in higher education
}

$I^{\mathrm{n}}$ n early March 2007, ACRL, in conjunction with EDUCAUSE and the National Association of College Stores (NACS), sponsored a forum in Denver to explore new areas of collaboration between libraries, information technology, and college stores in the new information environment. Approximately 40 invited participants gathered at the Grand Hyatt Denver for an intensive two days of discussion and brainstorming on the ways in which the associations and their membership can "help ensure the continued success of the nation's colleges and universities by addressing opportunities presented by the emergence of new modes of information delivery." Stated objectives of the forum included identifying areas of both common and unique knowledge among the stakeholders and recommending courses of action to improve communication and relationships across campus constituencies.

\section{Introductory session}

The introductory session convened to discuss the goals of the forum and examine some of the major issues facing colleges and universities in the new information environment. Participants viewed and discussed a provocative video presentation on the future of higher education in 2020, which served as the basis for discussion in break out sessions over the next two days. General issues raised for discussion included creation, reservation, and distribution of materials on campuses along with strategies to improve the ways in which students acquire information both in and out of the classroom. Questions of storage and accessibility of materials created by faculty and others in the academy over the long term also proved to be a major discussion point. Librarians, IT professionals, and college store personnel all have vested interest in the process of scholarly communication and will need to work together outside of their normal roles to ensure continued access to and preservation of digital content. Participants identified several additional issues, including globalization and economic concerns, where increased collaboration will be essential to the success of the academy.

The remainder of the day was devoted to a series of small group exercises during which members from each stakeholding group were divided into teams to examine in more detail the vision of the future presented in the opening sessions and identify major issues facing higher education over a timeline. A majority of members of each working group were from one area of expertise, with a smaller number of members of other groups included. This cross-pollination of roles provided for interesting discussion and introduction of new ideas as each group was to identify both positive and negative developments for the future of information delivery in the academy.

\section{Issues raised}

The majority of library groups identified issues of open access, print on demand, librarians as equal members of research teams, and simplification of copyright issues as positive future developments, while the continued

David Free is public services librarian at Georgia Perimeter College-Decatur Campus Library, e-mail: dfree@gpc.edu

() 2007 David Free 
information divide, standardization of class content, and the increasing commercialization of higher education were negatives. The information technology work groups focused on issues of network security and hosting, the increasingly multidimensional content environment, user expectations, and increased integration and interconnectedness between IT and libraries. Increased student adoption of digital content with related revenue issues, aggregation of content, and the future of bookstores in general, with an increasing move away from paper formats, were among the major points of discussion in the college stores groups. At the end of the session, each group presented its vision of higher education over the next 20 years in the form of a timeline. This process forced participants to think about the major issues impacting their primary area of responsibility and opened lines of communication and increased understanding.

\section{Collaboration opportunities}

The functional area working groups reconvened the following day with some membership changes to introduce new voices and increase input from other areas. Working from the previous days' timelines, each group identified two or three major potential opportunities for collaboration. Issues of repositories and open access were strong in the library groups. Increasing access to materials in the new electronic environment will require cross-institutional collaboration in repositories to conceptualize, manage, and develop new means of access to digital content. The current system of publisher- or institution-based digital storage makes successful search and retrieval difficult, a fact that could be improved with increased collaboration between functional groups and across institutional boundaries. Learning objects will have to potentially incorporate aspects of tagging, social bookmaking, and other Web 2.0 tools in order to facilitate this model of increased access.

Libraries need to become a more integral part of scholarly discussions by continuing to reach out to classroom faculty. Increased understanding of scholarly processes and discussions by librarians will help foster this collaboration, along with physical space for stakeholders from various groups to meet and discuss scholarly issues.

Top opportunities identified by the information technology groups included refocusing the IT unit on teaching and learning, creating content access portals to make all content readily available, and aggregating digital resources. The pace of adopting new technologies must increase in order to meet these goals.

Facilitation of communication and discussion between all three groups represented in Denver, along with classroom faculty and students, is increasingly important in his new environment. Interestingly, these issues were very closely aligned with the library ideas on open access and content delivery across institutional lines. Mass digitization of learning materials will require input and shifted roles from all groups to create and provide access to new forms of content.

The bookstore-dominated groups focused on issues related to physical space and resource centers. In the future, college stores must partner with an increasing number of campus areas to become part of multidisciplinary resource centers to better serve all constituency groups. Moving bookstores from a purely retail model toward becoming a campus service solution through the distribution of digital content, collaboration on licensing content campus wide, and taking advantage of customer relationships will serve to improve communication and ensure the place of college stores on the campus of the future.

Bookstores can create a type of "trip advisory" resource for instructional content modeled on online travel sites by collaborating with libraries in using social software and other new technologies to provide increasingly integrated access to customized, personalized learning materials. Bookstores and libraries also have opportunities to jointly provide faculty concierge services to assist in the selection and creation of materials. 


\section{Team work}

The final exercise of the forum merged participants into three groups-college stores and libraries, libraries and IT, and IT and college stores-to further distill the ideas discussed in previous session and identify top areas for potential real world collaboration. The college stores and libraries team identified ideas for collaborative physical and virtual space as the top-rated opportunity. Combining the expertise of both groups has the potential to create both online and on-campus spaces, where the entire academic community can gather, discuss issues, and learn. Working outside of existing silos to remove perceived barriers will greatly assist in this process. The strengths of each group in networking, materials acquisition, and financial transactions can be harnessed in a collaborative environment to more efficiently facilitate the delivery of information to students and faculty. For example, libraries can potentially turn over financial transactions related to materials acquisitions and database licensing to college stores. This type of collaboration plays to the strengths of each group and frees each to focus on its particular areas of expertise.

Issues of space also played a major role in the discussion between libraries and IT. Working together to create academic information spaces to facilitate the discovery of digital objects and information through more effective aggregation will benefit the academy as a whole. This academic information space can centralize copyright clearance and rights management expertise to facilitate more effective creation of course packets and digital materials for use in courseware. As copyright and rights management issues become increasingly complex due to the proliferation of digital formats, this type of collaborative environment is increasingly important in the delivery of learning content. Aggregating information delivery and creation can potentially produce a streamlined and more efficient environment for disseminating information to both faculty and students.

The IT and college stores group focused on several related issues and ideas, includ- ing providing the academic "trip advisor" services developed during the previous sessions. Using and supporting Web 2.0 tools as a means to developing advisory structure for the creation of instructional content will allow for the development of a consultative relationship between all represented groups and classroom faculty to integrate new forms of content into the curriculum. Libraries and bookstores can become increasingly embedded into the instructional process by taking advantage of the skills inherent in the information technology environment in the creation of digital materials and spaces. The increasing move towards a business model of academia may potentially provide new opportunities to monetize bookstore and library expertise for the benefit of both groups. By working together and building on existing relationships, all groups can more effectively advocate for change and improve instruction and access to information across the board.

\section{Closing}

After a grueling and intense two days of learning, sharing, and collaborating, the forum ended with a reflective session on the experiences and lessons learned. As ACRL Executive Director Mary Ellen Davis noted in her closing remarks, a major end result of the forum was the increased realization and recognition of potential areas of collaboration between the three represented groups. Many participants shared this sentiment, especially in relation to the bookstore/library relationship. Representatives from both communities observed that they now saw each other as potential colleagues and partners in their institutions.

While libraries and college stores both have interaction with information technology professionals on some level, they had not thought of each other as collaborators or partners prior to coming together in Denver. While this was the major realization in terms of new partnerships, all participants developed new respect and ideas for working

(continues on page 363) 
multaneously trying to add a bit of the new, they are allied with neither the past nor the future; they are rarely seen as strong and sustainable advocates of the future of the institution. In this time of resource limits and challenge from virtually every stakeholder, courageous choices are necessary. If librarians are to play an active and constructive role in creating the future of their institutions, including their own future in supporting education and scholarship, then they must start with open-eyed examinations of their strengths and weaknesses, not an evaluation based on past or current habits, but on the competencies and weaknesses that underlie current practice.

I am reminded of an earlier era of computing, the mainframe days, when to use a computer one needed to go to the impressive campus computer center for access. Coffee and snacks were available. Various support offices were located there and open for long hours. There were large areas with tables to facilitate group work, because we needed to be taught by each other as we learned. These centers were made anachronisms by personal computers, and became empty, even as the effectiveness of the tools provided by computers increased.

Personal computers didn't make the physical library anachronistic, but the rapid growth of vast quantities of Internet-based anywhere/anytime information is a real challenge to libraries and librarians. Over the long term these challenges will not likely be addressed by increasing the noninquiry reasons for coming to libraries (e.g., coffee shops and group-study spaces), but by thinking in new ways about how libraries and librarians can serve the inquiring mind. These new ways should not be based on the current practices of libraries as places, but on the underlying competencies and strengths of the profession.

My great oak table, once designed for the reading room of a library and capable of holding tall stacks of books and periodicals, is no longer in that setting nor is it used for that purpose. It is now in my home office, where my most creative inquiry happens, and instead of holding up books and periodicals (though I will admit that it does hold up some of them), it is the base for my Internetconnected computers. While cracked and a bit warped, it serves today's new needs as effectively as it did yesterday's needs - and indeed, supports a much more effective and efficient process of inquiry today than it ever did in the past.

Where is the value in libraries and librarians? There are many and they are strong, and as previous CERL News columns have indicated, there are many ways to communicate them. But if the future of the library is to be strong, then librarians must demonstrate that they are moving beyond the past and making choices today that directly serve the needs of tomorrow's inquiring mind. $\nsim$
("Stepping through..." cont. from page 358)

together for the benefit of the educational process.

While there are potential barriers to effectively enacting many of the ideas brought forward at the forum, all of the sponsoring associations expressed a need to continue to work together and discuss collaborative issues on a national level. Presenting joint panel discussions at the major conferences of each organization and cross-organizational work through committees were major ideas expressed to potentially continue and expand the conversations started in Denver. Adding stakeholders, such as university presses and classroom faculty, to the mix can serve to broaden the discussions. Continuing the conversations begun in Denver through additional forums and online or face-to-face presentations and repositories of successful real world collaborative projects can ensure that all stakeholders step through the door opened by technological innovation for the benefit of their individual institutions and the improvement of higher education. $\mathbf{z}$ 